\title{
Urban vultures preferentially roost at sites surrounded by more developed land cover and lower deer carcass density.
}

Hannah Partridge ( $\nabla$ hpartrid@uncc.edu )

University of North Carolina at Charlotte https://orcid.org/0000-0002-0025-4452

Sara Gagné

University of North Carolina at Charlotte

\section{Research Article}

Keywords: black vulture, turkey vulture, North Carolina, roost, urbanization, management

Posted Date: April 6th, 2022

DOI: https://doi.org/10.21203/rs.3.rs-1315893/v2

License: (a) (i) This work is licensed under a Creative Commons Attribution 4.0 International License. Read Full License 


\section{Abstract}

Land cover changes resulting from urbanization alter habitat structure and resource availability. Vultures provide ecosystem services such as nutrient cycling and may help limit disease transmission, making them an important feature of urban areas. Urbanization may have positive and negative impacts on vultures, such as increasing foraging opportunities and decreasing nesting success, complicating our understanding of the effect of urbanization on these species. We examined how local and landscape features affect roost attendance of black vultures (Coragyps atratus) and turkey vultures (Cathartes aura) to better understand the factors that play a role in site selection and habitat and landscape use. We counted the number of vultures at twenty-nine roosting sites in the Charlotte Metropolitan Area, NC once a month between November and March over two years. At each roosting site, we measured roosting structure height, vegetation height, and open space, and calculated the amounts of developed land cover, open water, developed-forest edge density, and deer carcass density in surrounding landscapes of 0.4 to $20 \mathrm{~km}$ radii. The best model for roost attendance included wind speed, vegetation height, developed land cover within $15 \mathrm{~km}$, developed-forest edge density within $15 \mathrm{~km}$, deer carcass density within 15 and $20 \mathrm{~km}$, and survey date. Developed land cover was associated with higher roost attendance while other variables were associated with lower roost attendance. The effects of landscape variables on roost attendance suggests urban vultures are relying more on trash and anthropogenic food sources, which may alter nutrient cycling, disease dynamics, and reproductive success.

\section{Introduction}

By 2040, the global human population is projected to be greater than 9 billion, with $68 \%$ of people living in urban areas (United Nations 2019). Populations growing at these rates require more infrastructure, bringing increased levels of traffic, pollution, and disturbance to natural environments and wildlife populations. Land cover changes that result from this increasing urbanization reduce and degrade critical bird habitats on local and global scales (Isaksson 2018). Many species cannot persist in these altered conditions, leading to decreased diversity and few successful species in highly urbanized areas (Faeth et al. 2011).

Vultures within the Cathartidae family include several of these successful species, to the point that they are often seen as nuisances in cities (Blackwell et al. 2007). Cathartid vultures have adapted to cities well, using human-made structures for roosting, foraging, and nesting across North and South America (Avery et al. 2002; Coles 1944; Hill III and Neto1991). Historically, vultures roosted on trees and other natural structures in largely undeveloped areas (Coleman and Fraser 1989; McVey et al. 2008; Rabenold and Decker 1990). Today, urban vulture roosts are commonly found on artificial structures such as transmission towers, cellular towers, and water towers across the United States, representing a dramatic change in behavior over a relatively short time span (Avery et al. 2002; Seamans 2004). Vultures also benefit from roadkill, landfills, and residential land cover in cities for foraging (Novaes and Cintra 2015; Thompson et al. 1990), although foraging opportunities may be dependent on sanitation practices, which can change over time (Coleman and Fraser 1989; Houston et al. 2007; Stewart 1974). Vultures would naturally nest in caves and tree cavities but have begun nesting in abandoned buildings and other human structures, making them more vulnerable to habitat loss and disturbance during the nesting season, which can dramatically reduce nest success (Coleman and Fraser 1989; Houston et al. 2007; Stewart 1974). 
In our study area in the southeastern United States, black vultures (Coragyps atratus) and turkey vultures (Cathartes aura) are common sights in urbanized areas, despite previous population declines (Robbins et al. 1989). Previous research has reported black vultures occurring near foraging sites, such as street markets and garbage dumps, possibly to reduce movement costs in developed landscapes (Novaes and Cintra 2013). Campbell (2014) found that black vulture numbers show strong positive associations with highly urbanized areas, being commonly found in city centers and suburbs, likely due to increased food availability in these areas (Campbell 2014). Turkey vultures are also associated with urbanized areas, but to a lesser extent than black vultures as they tend to range farther and forage on less predictable sources (Campbell 2014).

Vultures are specialized for scavenging, with efficient soaring flight, bald heads, and extremely corrosive stomach acid that allows them to consume carcasses infected with diseases without becoming infected themselves (Ogada, Keesing, et al. 2012). As such, vultures carry out a vital function in urban ecosystems by disposing of carcasses and organic matter that could otherwise spread deadly diseases to other scavengers and ultimately human populations. By scavenging, vultures also play an important role in nutrient cycling at the relatively large spatial scales over which they forage (Hill et al. 2018).

Despite the importance of vultures to ecosystem functioning and their increasing prevalence in urban landscapes, we know very little about the factors underlying their success. Our objectives for this study were to assess the impact of several local and landscape features on vulture roost attendance. In the Charlotte Metropolitan Area, we used vulture roost surveys, local habitat surveys, and geospatial analyses to evaluate the effects of time and weather conditions, local habitat structure, landscape structure, and landscape deer carcass density on the roost attendance of black and turkey vultures at 29 roosting sites over two years. Based on previous studies and personal observations, we expect developed land cover to positively impact roost attendance due to vultures readily taking advantage of anthropogenic structures and resources.

\section{Materials And Methods}

\section{Study area}

The Charlotte Metropolitan Area (CMA) is composed of 12 counties in North and South Carolina, USA surrounding the city of Charlotte, North Carolina $\left(35.22^{\circ} \mathrm{N}, 80.86^{\circ} \mathrm{W}\right)$ and covering an area of $8,280 \mathrm{~km}^{2}$. The CMA human population is estimated at 2.8 million, with rapid growth since 2010 (U.S. Census Bureau 2019). The population of Mecklenburg County, within which Charlotte is located, is expected to grow by over 570,000 between 2010 and 2040 with an annual growth rate of 2.3\% (Charlotte Future 2019).

The Charlotte city center consists of a concentration of developed land cover types, but development across the entire CMA is fairly sprawling and dominated by developed open space and single-family housing. Forested land, primarily deciduous, accounts for nearly $50 \%$ of the CMA, whereas pasture and hayfields account for just over $20 \%$. Wetlands, natural grasslands, and open water are relatively rare. Elevations in the region range between 93 and 780 meters and the climate is humid continental, with average summer highs of $32^{\circ} \mathrm{C}$, average winter lows of $-1^{\circ} \mathrm{C}$, and average annual precipitation of $116 \mathrm{~cm}$ (U.S. Climate Data 2021).

\section{Roosting sites}


We identified 15 black vulture and turkey vulture communal roosting sites within the CMA in 2019 and an additional 14 in 2020 for a total of 29 roosting sites (Fig. 1). Selected roosting sites were located by the lead author using a list compiled by Mecklenburg Audubon Society (MAS) members, eBird reports, and personal observations of vulture movements across the CMA at sunrise and sunset (totaling approximately 80 hours). Our use of multiple sources of information to locate roosting sites helped to maximize roosting site sample size and minimize any potential spatial bias in roost location due to the preferential selection of easily visible sites near roads and/or other development. Prior to being included in the study, all reported and observed roosting sites were checked for vulture presence and type of roost. We selected roosting sites that hosted vultures overnight and excluded temporary roosts used during the day as resting and congregating sites prior to or immediately following overnight roosting.

Twenty-seven roosts were located on transmission or cellular towers. Roosts on transmission towers (22) were situated in right-of-way (ROW) corridors with forest on either side, whereas roosts on cellular towers (5) were not located in right-of-way corridors and were adjacent to a variety of land covers. The two roosts not located on towers were on small clusters of deciduous trees within $1 \mathrm{~km}$ of transmission towers and adjacent to residential development.

\section{Roost surveys}

We counted the number of vultures at each roost once a month from November 2019 to March 2020 and from November 2020 to March 2021, for a total of five surveys per roost per year. Thirteen roosts were surveyed in both years and 16 roosts were surveyed in a single year. Survey periods coincided with the non-nesting season during which vultures use roosts most consistently by returning to the same roost night after night and in the largest numbers (Sweeney 1984). During each survey, we counted vultures at roosts between 30 minutes before and 30 minutes after sunrise when individual vultures could be distinguished as they became more active and spread out on the roosting structure but before they left the structure to forage in the surrounding landscape (Sweeney 1984). During the second year of surveys, the count period was shortened to only the 30 minutes before sunrise as a result of observations in the previous year that vultures often left roosting sites earlier than expected (see the Analyses section below for the correction applied to first year data to account for this difference in survey methods). Trained volunteers assisted the authors in conducting surveys in both years.

\section{Explanatory variables}

Local variables We measured local weather and habitat variables at each roosting site that may be important in explaining vulture attendance including air temperature, wind speed, cloud cover, roosting structure height, surrounding vegetation height, and open space (Table 1). Vultures generally remain at or near roosting sites longer during colder temperatures or inclement weather (Sweeney and Fraser 1986). However, on windy mornings, vultures may be more likely to leave the roost earlier, perhaps to take advantage of wind currents for early-morning foraging flights (Davis 1979). We measured roosting structure height, surrounding vegetation height, and open space to account for the physical characteristics of roosting sites that may aid in arrival, departure, and flight ease. Open fields or corridors surrounding roosting sites allow unobstructed arrival and departure and may provide upward air currents (Coleman and Fraser 1989; Davis 1979). The same benefits 
may be provided by the height of the roosting structure, with structures above tree level providing easier access.

Table 1

Potential explanatory variables of black vulture (Coragyps atratus) and turkey vulture (Cathartes aura) roost attendance in the Charlotte Metropolitan Area, USA. Developed land cover, Open Water land cover, DevelopedForest edge density, and deer carcass density were measured for landscapes with radii of $0.4,0.5,1,2,3,4,5$, 10,15 , and $20 \mathrm{~km}$.

\begin{tabular}{|c|c|c|c|}
\hline Variable & Type & $\begin{array}{l}\text { Spatial } \\
\text { scale }\end{array}$ & Data source \\
\hline $\begin{array}{l}\text { Number of } \\
\text { vultures }\end{array}$ & Response & NA & Sunrise roost surveys \\
\hline $\begin{array}{l}\text { Air } \\
\text { temperature }\end{array}$ & Explanatory & Local & $\begin{array}{l}\text { Weather Underground Personal Weather Stations (Weather } \\
\text { Underground, 2021) }\end{array}$ \\
\hline Wind speed & Explanatory & Local & $\begin{array}{l}\text { Weather Underground Personal Weather Stations (Weather } \\
\text { Underground, 2021) }\end{array}$ \\
\hline Cloud cover & Explanatory & Local & Visual estimate of percent cloud cover during roost surveys \\
\hline $\begin{array}{l}\text { Roosting } \\
\text { structure } \\
\text { height }\end{array}$ & Explanatory & Local & Clinometer and rangefinder measurements \\
\hline $\begin{array}{l}\text { Surrounding } \\
\text { vegetation } \\
\text { height }\end{array}$ & Explanatory & Local & Clinometer and rangefinder measurements \\
\hline Open space & Explanatory & Local & Google Earth and rangefinder measurements \\
\hline $\begin{array}{l}\text { Developed } \\
\text { land cover }\end{array}$ & Explanatory & Landscape & 2016 National Land Cover Database (Yang et al., 2018) \\
\hline $\begin{array}{l}\text { Open Water } \\
\text { land cover }\end{array}$ & Explanatory & Landscape & 2016 National Land Cover Database (Yang et al., 2018) \\
\hline $\begin{array}{l}\text { Developed- } \\
\text { Forest edge } \\
\text { density }\end{array}$ & Explanatory & Landscape & 2016 National Land Cover Database (Yang et al., 2018) \\
\hline $\begin{array}{l}\text { Deer } \\
\text { carcass } \\
\text { density }\end{array}$ & Explanatory & Landscape & $\begin{array}{l}\text { North Carolina Department of Transportation and Wildlife } \\
\text { Resources Commission (NCDOT, 2018), South Carolina } \\
\text { Department of Public Safety (SCDPS, 2018), and 2018 } \\
\text { TigerLine road shapefile (U.S. Census Bureau, 2018) }\end{array}$ \\
\hline Survey date & Explanatory & NA & NA \\
\hline
\end{tabular}

We collected data on air temperature and wind speed during each survey from Weather Underground Personal Weather Stations (PWS) (Weather Underground 2021) located near roosting sites. For each roosting site and survey, we used the PWS located nearest to the site and the air temperature and wind speed measurements at the start of the survey. During each survey, we also visually estimated percent cloud cover using a scale from $0-100 \%$ in $10 \%$ increments. 
In January of the year each roost was first surveyed, we measured the height of each roosting structure and surrounding vegetation using a Suunto PM-5/360 clinometer and Nikon Aculon rangefinder. Using the clinometer, we measured the angle of elevation from the viewpoint to the top of the roosting structure or the top of the trees surrounding the roosting structure. We defined the top of the roosting structure as the typical location of the highest roosting vulture. For roosts located on transmission towers, we took the average of the angle to the trees on either side of the ROW corridor. For all other roosts, we used the trees or other vegetation closest to the roosting structure. With the rangefinder, we measured the distance from the viewpoint to the base of the roosting structure or the base of the vegetation sampled with the clinometer. Heights were calculated by multiplying the angle tangents by distances.

We measured open space using Google Earth and confirmed the distance with a Nikon Aculon rangefinder. For roosts on transmission towers, open space was the width of the ROW corridor at the level of the tower. For other types of roosting structures, we measured multiple locations around the roosting structure and calculated the average width of open space surrounding the structure.

Landscape variables We chose four landscape variables to explain vulture attendance at roosts: amount of Developed land cover, amount of Open Water land cover, Developed-Forest edge density, and deer carcass density (Table 1). Developed land cover provides roosting and nesting structures and food sources that appear to attract vultures (Campbell 2014; Novaes and Cintra 2015; Thompson et al. 1990). Open water provides food and water for vultures. Vultures have also been found to frequently use edge habitat between open and forested areas, perhaps to benefit from the proximity of cover and foraging opportunities (Coleman and Fraser 1989; Novaes and Cintra 2015). Finally, previous research has found food availability to be a main predictor of the location of vulture roosting sites (Campbell 2014; Novaes and Cintra 2015), with roadkill potentially being an important food resource for vultures in urban landscapes (Thompson et al. 1990).

Each variable was measured in landscapes with radii of $0.4,0.5,1,2,3,4,5,10,15$, and $20 \mathrm{~km}$ centered on roosting sites. Landscape scales encompassed variation in estimates of space use by black and turkey vultures. Holland (2015) reported a maximum core area size of $0.45 \mathrm{~km}^{2}$ for black vultures and $0.42 \mathrm{~km}^{2}$ for turkey vultures, maximum home range size as 30-60km, and Houston et al. (2011) reported turkey vulture home ranges over $900 \mathrm{~km}^{2}$.

We measured the amount of developed land cover and the amount of open water land cover in landscapes as the proportion of each landscape covered by the Developed classes or the Open Water class of the 2016 National Land Cover Database (Yang et al. 2018). We measured the Developed-Forest edge density of each landscape as the length of edge between any Developed class (Open space, Low intensity, Medium intensity, and High intensity) and any Forest class (Deciduous, Evergreen, Mixed) of the 2016 National Land Cover Database divided by landscape area.

We used 2018 TigerLine road data (U.S. Census Bureau 2018) and 2018 white-tailed deer (Odocoileus virginianus) collision data (NCDOT 2018; SCDPS 2018) to estimate deer carcass density in landscapes. For landscapes in North Carolina where deer collisions are tracked by road segment, we first calculated the number of deer collisions and total road length, using only road types on which deer collisions were recorded. The number of deer collisions was then divided by total road length and then again by landscape area. In 
contrast, the South Carolina Department of Transportation tracks the number of deer collisions by county. We therefore had to estimate the number of deer collisions in landscapes in South Carolina by multiplying the number of deer collisions in each county in a landscape by the areal proportion of the county overlaid by the landscape, summing the resulting deer collisions across counties, and dividing by landscape area. Deer carcass densities for landscapes that overlapped the state boundary were multiplied by the proportional area of the landscape in the state prior to averaging. Landscape variables were calculated using ArcGIS Pro, v2.5.0 (ESRI 2020) and FRAGSTATS, v4.2.1.603 (McGarigal et al. 2015).

\section{Analyses}

During the 2019-2020 roost survey season, we observed that vultures often left roosting sites earlier than expected - in some cases, most vultures were gone by 30 minutes after sunrise. Starting in March of 2020, we conducted surveys within only 30 minutes before sunrise in order to ensure an accurate count of roosting vultures for the remainder of the study.

We corrected for any bias resulting from vultures leaving roosting sites earlier than expected by conducting additional counts of roosting vultures in relation to time before and after sunrise to estimate the rate at which vultures leave roosting sites. The lead author counted the number of vultures roosting every minute from 60 minutes prior to sunrise to 60 minutes after sunrise at eight different roosting sites over 16 days from September 2019-March 2020. We then used a 6th order polynomial regression to model the proportion of the roost remaining with respect to time before and after sunrise $\left(F_{6,1042}=262.30, p<0.001\right.$, adjusted $R^{2}=0.60$; Figure A1). All roost counts from 2019-2020 and 2020-2021 were adjusted by dividing the count by the predicted proportion of the roost remaining at the time the count was conducted.

We identified the local and landscape features associated with the adjusted number of vultures at roosts using repeated measures, generalized linear mixed-effects models, multi-model inference, and simultaneous autoregressive models. All models included a random site effect to account for the non-independence of observations from the same roosting site. Models also included survey date, measured as Julian date, i.e., the number of days since the beginning of the Julian period in $4713 \mathrm{BC}$, to account for variation in roost attendance across months and years (Sweeney and Fraser 1986). We restricted landscape variables in models to those from the same spatial scale in order to minimize high levels of collinearity among explanatory variables. Collinearity among local and landscape variables in models was below thresholds above which levels are deemed unacceptable ( $r<0.70$ and VIF $<10$ (Dormann et al. 2013); Appendix A), except for the correlations between Developed-Forest edge density and Developed land cover within $10 \mathrm{~km}, 15 \mathrm{~km}$, and $20 \mathrm{~km}(0.72 \leq \mathrm{r} \leq 0.79)$ (Tables A1-A11). We divided explanatory variables by their partial standard deviations (standard deviations divided by VIF values, sample size, and the number of predictor variables (Cade 2015)) and we also standardized explanatory variables. Finally, we log-transformed the response variable in models to address heteroskedasticity in residuals.

We evaluated models containing all possible combinations of explanatory variables, with the exception that models contained only landscape variables from the same spatial scale, using $\mathrm{AlC}_{\mathrm{c}}$. As roosting sites were spatially clumped in our study area, we tested for spatial autocorrelation in the residuals of the best models $\left(\Delta \mathrm{AlC}_{\mathrm{c}}<2\right)$ (Burnham and Anderson 2002) using correlograms, Moran's I, and Bonferroni-corrected p-values. 
Most residuals exhibited significant spatial autocorrelation (Figures A2-A8). To account for this source of variation, we re-analyzed the top models as simultaneous autoregressive models of the spatial error type $\left(S A R_{\text {err }}\right)$ using the distance at which spatial autocorrelation was most pronounced in correlograms to define neighborhoods.

We calculated model-averaged effect sizes of explanatory variables in SAR $\mathrm{err}_{\text {models }}$ and their unconditional variances (Burnham and Anderson 2002). All effect sizes for each explanatory variable were unimodal (Cade 2015). We used RStudio v1.3.1073 (RStudio Team 2020) and the MuMln v1.43.17 (Barton 2020), car v3.0-11

(Fox and Weisberg 2018), spdep v1.1-11 (Bivand and Wong 2018), ncf v1.2-9 (Bjornstad 2020), Ime4 v1.1-27.1 (Bates et al. 2014), spatialreg v1.1-8 (Bivand and Piras 2015) and ggplot2 v3.3.5 (Villanueva and Chen 2019) packages to carry out analyses.

\section{Results}

Seven models qualified as the best models $\left(\Delta \mathrm{AlC}_{\mathrm{c}}<2\right)$ describing vulture roost attendance (Table 2$)$. Models included wind speed, surrounding vegetation height, Developed land cover within $15 \mathrm{~km}$ of roosting sites, Developed-Forest edge density within $15 \mathrm{~km}$ of roosting sites, deer carcass density within $15 \mathrm{~km}$ and $20 \mathrm{~km}$ of roosting sites, and survey date. The number of vultures was larger at roosting sites bordered by lower vegetation and surrounded by landscapes with lower carcass densities, lower developed-forest edge densities, and more developed land cover (Figs. 2-3).

Table 2

The top models $\left(\triangle \mathrm{AlC}_{\mathrm{c}}<2\right)$ describing black vulture (Coragyps atratus) and turkey vulture (Cathartes aura) roost attendance in the Charlotte Metropolitan Area, USA.

Variables include wind speed (WIND), surrounding vegetation height (VEG), the amount of developed land cover within $15 \mathrm{~km}$ of roosting sites (DEV_15), developedforest edge density within $15 \mathrm{~km}$ of roosting sites (EDGE_15), deer carcass density within $15 \mathrm{~km}$ of roosting sites (DEER_15) or 20km of roosting sites (DEER_20), and survey date (DATE).

\begin{tabular}{|lccccl|}
\hline Model & df & logLik & AICc & $\Delta$ AlC $_{\mathbf{c}}$ & Akaike weight \\
\hline VEG + DEER_20 & 5 & -265.06 & 540.42 & 0.00 & 0.23 \\
\hline VEG + EDGE_15 & 5 & -265.36 & 541.00 & 0.59 & 0.17 \\
\hline VEG + DATE + DEER_20 & 6 & -264.33 & 541.07 & 0.65 & 0.17 \\
\hline VEG + DATE + EDGE_15 & 6 & -264.70 & 541.80 & 1.39 & 0.12 \\
\hline VEG + WIND + DEER_20 & 6 & -264.72 & 541.85 & 1.43 & 0.11 \\
\hline VEG + DEER_15 + EDGE_15 & 6 & -264.78 & 541.98 & 1.56 & 0.11 \\
\hline VEG + DEV_15+EDGE_15 & 6 & -264.98 & 542.38 & 1.96 & 0.09 \\
\hline
\end{tabular}

\section{Discussion}


Our results indicate that urban vulture roost attendance depends on local weather and habitat conditions, and landscape structure and deer carcass density at large spatial scales. More vultures were counted at roosting sites adjacent to lower vegetation heights and surrounded by landscapes with more developed land cover, less developed-forest edge density, and lower deer carcass density. More vultures were also counted at roosting sites when wind speed was lower. In the following, we discuss the possible reasons underlying the effects of local habitat and weather conditions on vulture roost attendance and posit that the effects of landscape variables on roost attendance suggest that urban vulture populations may be relying more on anthropogenic food sources than on roadkill and possibly other natural food sources. We conclude by discussing the implications of our results for the management of urban vulture populations.

Surrounding vegetation height and wind speed were each negatively associated with vulture roost attendance in our study area. Shorter vegetation surrounding the roosting site may allow vultures easier access to the roosting structure and make departure flights easier. Vultures at many of our sites flew directly from the roost to a nearby foraging area before sunrise. Easy entry and departure from the roosting site, made possible by shorter vegetation, may facilitate such directed movements and thus play a role in vulture roosting site selection. The negative effect of wind speed on vulture roost attendance in our study is supported by prior evidence suggesting that vultures choose favorable microclimates at roosting sites that reduce wind speed (Thompson et al. 1990). Future studies should employ anemometers installed on roosting structures to test this hypothesis.

A negative effect of developed-forest edge density within $15 \mathrm{~km}$ of roosting sites was included in four of the seven top models of roost attendance. Black and turkey vultures use a variety of habitats and resources found in urban and forested areas such as trees and transmission towers for roosting, roadkill and other carcasses for food, and buildings in forested areas for nesting (Coleman and Fraser 1989; Novaes and Cintra 2015). Yet, our results show a strong negative relationship between vulture roost attendance and developed-forest edge density, indicating that the vulture populations in our study area may be concentrating their activities in particular habitat types rather than at edges. The positive effect of developed land cover that we report supports this contention.

The positive effect of developed land cover on roost attendance and the strong negative effect of deer carcass density together suggest that urban vulture populations may be relying less on roadkill, and possibly other natural food sources, and more on trash and other anthropogenically-derived food. Food availability appears to be a primary factor in vulture occurrence (Campbell 2014; de Araujo et al. 2018; Novaes and Cintra $2013,2015)$ and the large amounts of easily accessible trash and food waste found in urban areas may be attracting large urban vulture populations. During our study, we observed black vultures flying directly to the same foraging sites each day and regularly congregating in large groups at restaurant dumpsters and other sites with readily available food. This change in urban vulture diet likely has important implications for nutrient cycling and disease dynamics in urban systems, with urban carcasses being consumed more slowly and by different species that may be more susceptible to pathogens (Morales-Reyes et al. 2017; Ogada, Torchin, et al. 2012). In addition, the scattering of anthropogenic materials and foods across landscapes by urban vultures, e.g., the creation of plastic islands in otherwise natural areas (Ballejo et al. 2021) could be an additional non-point source of pollutants. 
Vultures in our study area may be relying more on trash and other resources in developed land cover because of the relative abundance of these resources and because of the risk of mortality associated with foraging on road-killed deer. Several studies have found that species attracted to carcasses along roads face a higher risk of being hit by cars, with several vulture species facing an especially high risk (Husby 2016; Kociolek et al. 2015; Vidal-Vallés et al. 2018). As a result, vultures may be choosing to forage on readily accessible and abundant foods in developed land cover rather than on riskier roadkill.

Our results and their implications are likely more relevant to black vultures than turkey vultures. Most of the vultures counted during roost surveys were black vultures. Turkey vultures dominated the two tree roosts and all other roosts were primarily composed of black vultures. The natural roosts were within $1 \mathrm{~km}$ of large roosts on transmission or cellular towers and thus were surrounded by similar landscapes at most scales. However, compared to black vultures, turkey vultures concentrate their foraging on smaller, wild food items in forested areas, and are less likely to consume trash and other anthropogenic materials (Kirk and Mossman 2020). Future research should focus on the determinants of each species' occurrence and abundance in urban regions to better elucidate the generality of the patterns we report here.

As the black vulture range expands across the United States and conflicts between vultures and humans are becoming increasingly common in urban areas (Kluever et al. 2020), there is a greater need to understand their resource and landscape use to manage populations most effectively. Understanding the habitat and landscape preferences of these species can help land managers know where to deploy techniques to reduce or prevent populations from becoming nuisances. We have shown that black vultures and turkey vultures congregate in larger numbers at roosting sites surrounded by shorter vegetation and within landscapes composed of less developed-forest edge density, lower deer carcass density, and higher developed land cover. Assuming that food availability is the ultimate driver of roost attendance in the non-breeding season, the identification of suitable roosting sites in landscapes with these characteristics may enable managers to implement prevention measures, such as limiting the availability of trash before a conflict arises.

\section{Conclusion}

As urban areas continue to expand, it is important to understand how wildlife populations respond to changes in habitat structure and resource availability. We found that vulture roost attendance is negatively affected by wind speed and surrounding vegetation height at roosting sites and developed-forest edge density and deer carcass density in landscapes, and positively affected by the amount of developed land cover in landscapes. Importantly, these results imply that urban vultures are relying more on anthropogenic sources of food available in developed areas and less on roadkill and possibly other natural food sources. Future research should analyze the diet composition of urban and rural vultures to attempt to identify their primary food sources and to better understand the broader impacts that dietary changes may have on carcass decomposition, disease transmission, and pollution patterns in cities. Future research should also examine the species-specific responses of black and turkey vultures to habitat structure and resource availability in urban regions and the management strategies needed to prevent human-vulture conflicts. A deeper understanding of vulture distribution and occurrence in cities and their drivers will significantly advance the coexistence of these important species with humans. 


\section{Declarations}

Acknowledgements: This work was supported by a University of North Carolina at Charlotte Geology Scholars Award and a Mecklenburg Audubon Society Grant. We grateful thank the volunteers and the community members who assisted with fieldwork.

\section{Funding}

This work was supported by a University of North Carolina at Charlotte Geology Scholars Award and a Mecklenburg Audubon Society Grant.

\section{Competing Interests}

The authors have no relevant financial or non-financial interests to disclose.

\section{Author Contributions}

All authors contributed to the study conception, design, and analysis. Hannah Partridge wrote the first draft of the manuscript and Sara Gagné made significant edits to the drafts. All authors read and approved the final manuscript.

\section{Data Availability}

Analyses reported in this article can be reproduced using the data published on PANGAEA upon article acceptance.

\section{Code Availability}

All code will be made accessible upon article acceptance.

\section{Ethics Approval}

Not applicable.

\section{Consent to Participate}

Not applicable.

\section{Consent for publication}

All authors have read this manuscript and agreed to submission to Urban Ecosystems.

\section{References}

1. Avery ML, Humphrey JS, Tillman EA, Phares KO, Hatcher JE (2002) Dispersing vulture roosts on communication towers. USDA National Wildlife Research Center - Staff Publications, p 456 
2. Ballejo F, Plaza P, Speziale KL, Lambertucci AP, Lambertucci SA (2021) Plastic ingestion and dispersion by vultures may produce plastic islands in natural areas.Sci Total Environ, 755(142421)

3. Barton K (2020) Multi-model Inference. R package version 1.43.17

4. Bates D, Mächler M, Bolker B, and Walker S (2014) Fitting linear mixed-effects models using Ime4. arXiv preprint arXiv:1406.5823.

5. Bivand R, Piras G (2015) Comparing implementations of estimation methods for spatial econometrics.J Stat Softw, 63(18)

6. Bivand RS, Wong DW (2018) Comparing implementations of global and local indicators of spatial association. Test 27(3):716-748

7. Bjornstad ON (2020) ncf: Spatial Covariance Functions. R package version 1.2-9. In https://CRAN.Rproject.org/package $=$ ncf

8. Blackwell BF, Avery ML, Watts BD, Lowney MS (2007) Demographics of black vultures in North Carolina. J Wildl Manag 71(6):1976-1979

9. Burnham KP, Anderson DR (2002) Model selection and multimodel inference: A practical informationtheoretic approach, 2 edn. Springer, New York, NY

10. Cade BS (2015) Model averaging and muddled multimodel inferences. Ecology 96(9):2370-2382

11. Campbell MON (2014) The impact of urbanization and agricultural development on vultures in El Salvador. Vulture News 66:16-28

12. Charlotte Future (2019) Charlotte Future 2040 Comprehensive Plan Growth Factors Report. http://ww.charmeck.org/Planning/CompPlan/Charlotte_Growth_Factors.pdf

13. Coleman JS, Fraser JD (1989) Habitat use and home ranges of black and turkey vultures. J Wildl Manag 53:782-792

14. Coles V (1944) Nesting of the Turkey Vulture in Ohio caves. Auk 61:219-228

15. Davis D (1979) Morning and evening roosts of turkey vultures at Malheur Refuge, Oregon. Western Birds 10:125-130

16. de Araujo GM, Peres CA, Baccaro FB, Guerta RS (2018) Urban waste disposal explains the distribution of Black Vultures (Coragyps atratus) in an Amazonian metropolis: Management implications for birdstrikes and urban planning.PeerJ, 6, e5491

17. Dormann CF, Elith J, Bacher S, Buchmann C, Carl G, Carré G, Marquéz JRG, Gruber B, Lafourcade B, Leitão PJ (2013) Collinearity: a review of methods to deal with it and a simulation study evaluating their performance. Ecography 36(1):27-46

18. ESRI (2020) ArcGIS Pro 2.5.0. In Redlands. Environmental Systems Research Institute, CA

19. Faeth SH, Bang C, Saari S (2011) Urban biodiversity: patterns and mechanisms. Ann NY Acad Sci 1223(1):69-81

20. Fox J, Weisberg S (2018) An R companion to applied regression. Sage publications

21. Hill III JR, Neto PS (1991) Black Vultures Nesting on Skyscrapers in Southern Brazil (Buitres Anidando en Rascacielos en el Sur de Brasil). J Field Ornithol 62:173-176 
22. Hill JE, DeVault TL, Beasley JC, Rhodes OE Jr, Belant JL (2018) Effects of vulture exclusion on carrion consumption by facultative scavengers. Ecol Evol 8(5):2518-2526

23. Holland AE (2015) Spatial ecology of black and turkey vultures in the southeastern United States. Thesis, University of Georgia

24. Houston CS, Terry B, Blom M, Stoffel MJ (2007) Turkey Vulture nest success in abandoned houses in Saskatchewan. Wilson J Ornithol 119(4):742-747

25. Husby M (2016) Factors affecting road mortality in birds. Ornis Fennica 93:212-224

26. Isaksson C (2018) Impact of Urbanization on Birds. In: Tietze DT (ed) Bird species: how they arise, modify and vanish. Springer Nature

27. Kirk DA, Mossman MJ (2020) Turkey vulture (Cathartes aura). https://birdsoftheworld.org/bow/species/turvul/cur/introduction

28. Kluever BM, Pfeiffer MB, Barras SC, Dunlap BG, and Humberg LA (2020) Win) Black vulture conflict and management in the United States: damage trends, management overview, and research needs. Hum-Wildl Interact, 14(3)

29. Kociolek A, Grilo C, Jacobson S (2015) Flight doesn't solve everything: mitigation of road impacts on birds. In R. v. d. Ree, D. J. Smith, and C. Grilo (Eds.), Handbook of road ecology (pp. 281-289). WileyBlackwell

30. McGarigal K, Cushman SA, Ene E (2015) FRAGSTATS v4.2.1.603: Spatial Pattern Analysis Program for Categorical and Continuous Maps.. In Computer software program produced by the authors at the University of Massachusetts, Amherst. Available at the following web site: http://www.umass.edu/landeco/research/fragstats/fragstats.html

31. McVey KJ, Skrade PD, Sordahl TA (2008) Use of a communal roost by Turkey Vultures in northeastern lowa. J Field Ornithol 79(2):170-175

32. Morales-Reyes Z, Sánchez-Zapata JA, Sebastián-González E, Botella F, Carrete M, Moleón M (2017) Scavenging efficiency and red fox abundance in Mediterranean mountains with and without vultures. Acta Oecol 79:81-88

33. NCDOT (2018) 2018 Animal Crashes. https://connect.ncdot.gov/resources/safety/Crash\%20Maps\%20by\%20County/2018_Animal_Crashes.zip

34. Novaes WG, Cintra R (2013) Factors influencing the selection of communal roost sites by the Black Vulture Coragyps atratus (Aves: Cathartidae) in an urban area in Central Amazon. Zoologia (Curitiba) 30(6):607-614

35. Novaes WG, Cintra R (2015) Anthropogenic features influencing occurrence of Black Vultures (Coragyps atratus) and Turkey Vultures (Cathartes aura) in an urban area in central Amazonian Brazil. The Condor: Ornithological Applications 117(4):650-659

36. Ogada DL, Keesing F, Virani MZ (2012) Dropping dead: causes and consequences of vulture population declines worldwide. Ann NY Acad Sci 1249(1):57-71

37. Ogada DL, Torchin M, Kinnaird M, and Ezenwa V (2012) Effects of vulture declines on facultative scavengers and potential implications for mammalian disease transmission. Conserv Biol 26(3):453460

Page $13 / 18$ 
38. Rabenold P, Decker M (1990) Black vultures in North Carolina: statewide population surveys and analysis of Chatham County population trends

39. Robbins CS, Sauer JR, Greenberg RS, Droege S (1989) Population declines in North American birds that migrate to the Neotropics. Proceedings of the National Academy of Sciences, 86(19):7658-7662

40. RStudio Team (2020) RStudio: Integrated Development for R. In RStudio, PBC, Boston, MA. Available at http://www.rstudio.com/

41. SCDPS (2018) Deer Related Traffic Collisions, 2018-2019 (2019 Preliminary Data). Office of Highway Safety and Justice Programs, Statistical Analysis and Research Section. Unpublished data

42. Seamans TW (2004) Response of roosting turkey vultures to a vulture effigy. Ohio J Sci 104:136-138

43. Stewart PA (1974) A nesting of Black Vultures. Auk 91(3):595-600

44. Sweeney TM (1984) Black and turkey vulture roost dynamics, marking, morphology and nesting in Virginia. Dissertation, Virginia Polytechnic Institute and State University

45. Sweeney TM, Fraser JD (1986) Vulture roost dynamics and monitoring techniques in southwest Virginia. Wildl Soc Bull (1973-2006), 14(1):49-54

46. Thompson WL, Yahner RH, Storm GL (1990) Winter use and habitat characteristics of vulture communal roosts. J Wildl Manag 54:77-83

47. U.S. Census Bureau (2018) 2018 TIGER/Line Shapefiles (machine readable data files). Prepared by the U.S. Census Bureau

48. U.S. Census Bureau (2019) ACS Demographic and Housing Estimates. https://data.census.gov/cedsci/table? $q=$ population\&g=330M500US172\&tid=ACSDP1Y2019.DP05\&hidePreview=true.

49. U.S. Climate Data (2021) Climate Charlotte - North Carolina. https://www.usclimatedata.com/climate/charlotte/north-carolina/united-states/usnc0121

50. United Nations (2019) World Population Prospectus 2019. Population Division, Department of Economic and Social Affairs. United Nations

51. Vidal-Vallés D, Pérez-Collazos E, and Rodríguez A (2018) Bird roadkill occurences in Aragon, Spain. Anim Biodivers Conserv 41:379-388

52. Villanueva RAM, Chen ZJ (2019) ggplot2-Elegant Graphics for Data Analysis (2nd ed.). Measurement: Interdisciplinary Research and Perspectives, 17:160-167. https://doi.org/ 10.1080/15366367.2019.1565254

53. Weather Underground (2021) Personal Weather Station Network: Wundermap. https://www.wunderground.com/wundermap

54. Yang L, Jin S, Danielson P, Homer C, Gass L, Bender SM, Case A, Costello C, Dewitz J, Fry J (2018) A new generation of the United States National Land Cover Database: Requirements, research priorities, design, and implementation strategies. ISPRS J Photogramm Remote Sens 146:108-123

\section{Figures}




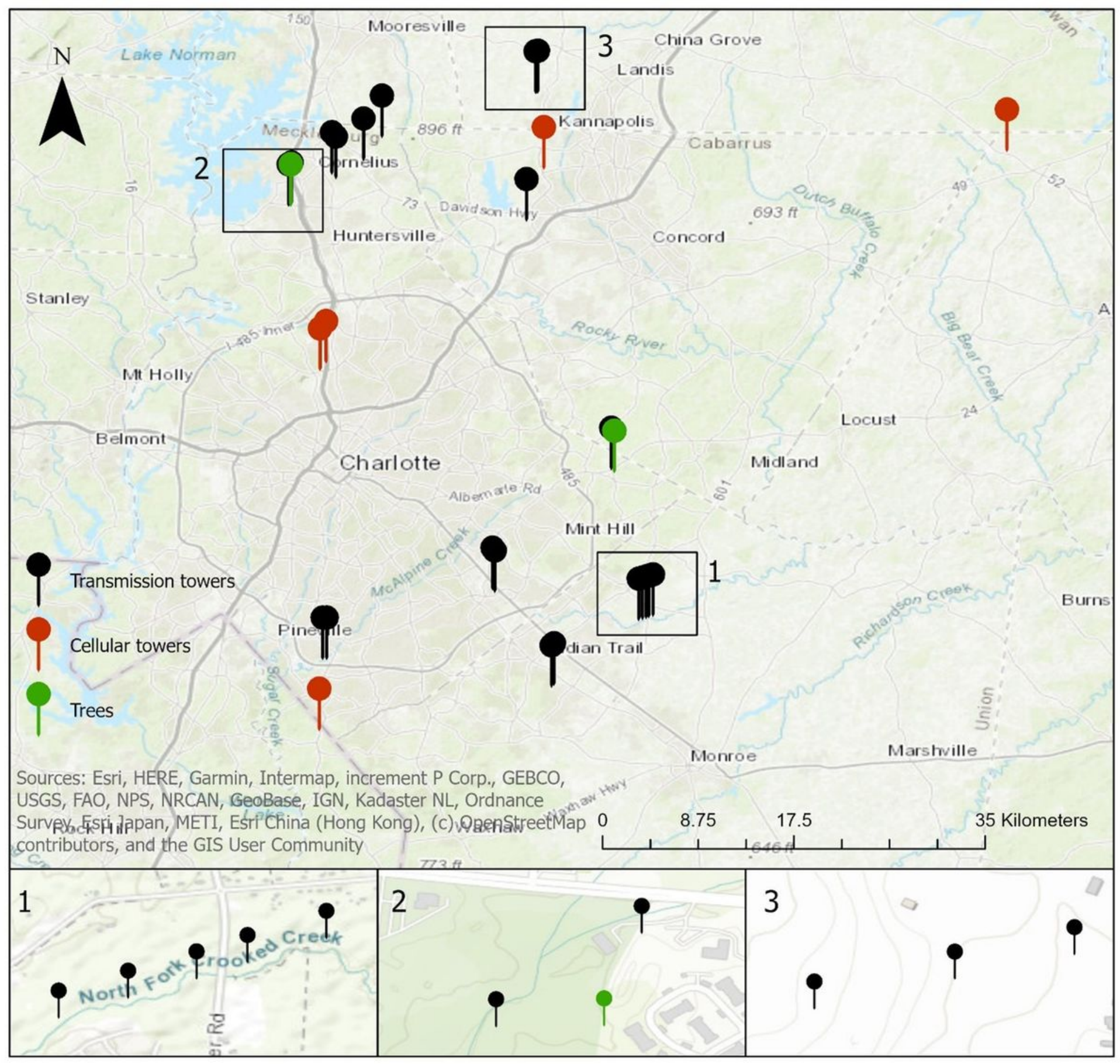

Figure 1

Black vulture (Coragyps atratus) and turkey vulture (Cathartes aura) communal roosting sites (29) within the Charlotte Metropolitan Area, USA, labelled by roosting structure type. Three areas with overlapping roost locations are shown as insets; other roost locations may overlap in the main map. The green shading represents vegetated areas, the gray represents developed areas, and the major water bodies are shown in blue 

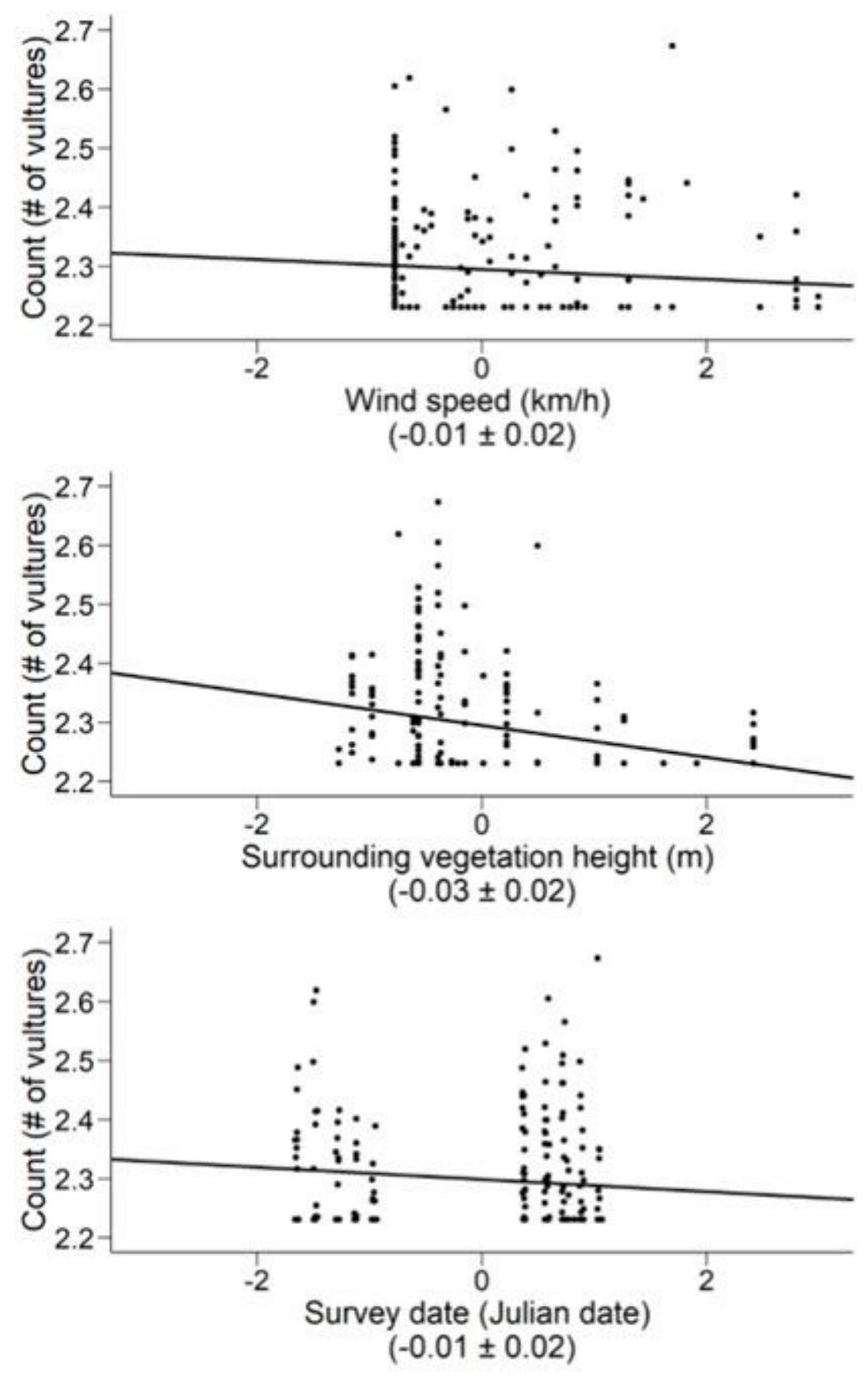

Figure 2

The effects of survey date and local explanatory variables in the top models $\left(\Delta \mathrm{AlC}_{\mathrm{c}}<2\right)$ describing black vulture (Coragyps atratus) and turkey vulture (Cathartes aura) roost attendance in the Charlotte Metropolitan Area, USA. Model-averaged standardized coefficients \pm 2 SE are in parentheses below variable names 


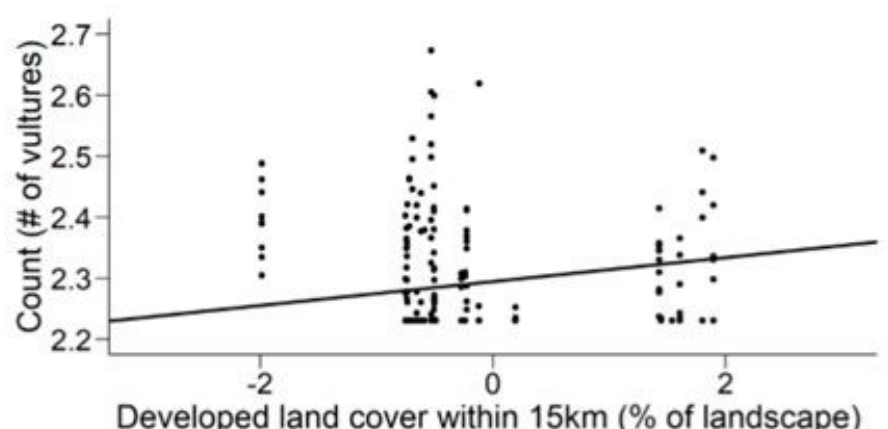

$(0.02 \pm 0.02)$

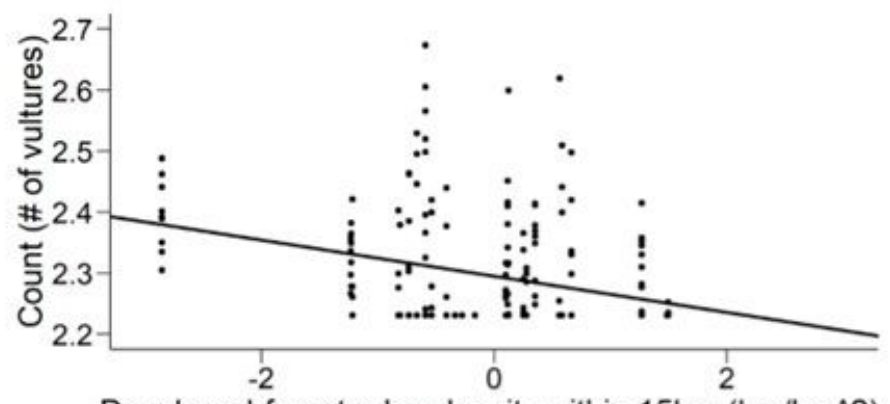

Developed-forest edge density within $15 \mathrm{~km}\left(\mathrm{~km} / \mathrm{km}^{\wedge} 2\right)$ $(-0.03 \pm 0.02)$
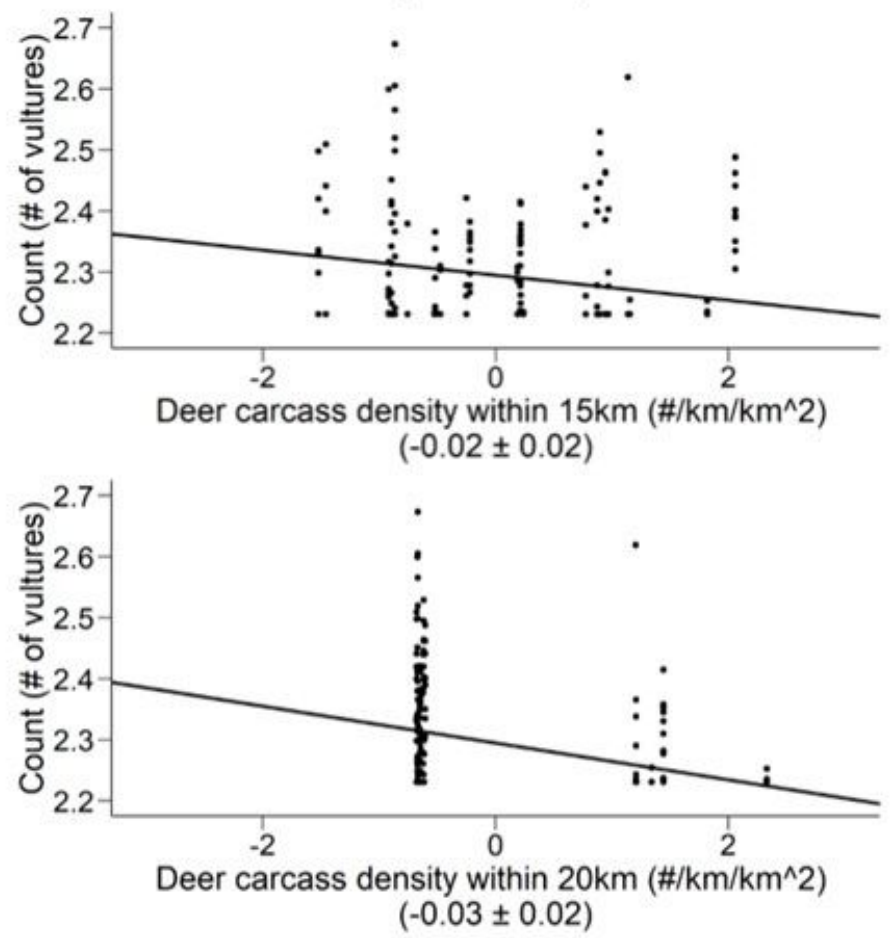

\section{Figure 3}

The effects of landscape variables in the top models $\left(\triangle \mathrm{AlC}_{\mathrm{c}}<2\right)$ describing black vulture (Coragyps atratus) and turkey vulture (Cathartes aura) roost attendance in the Charlotte Metropolitan Area, USA. Landscape variables were measured within $15 \mathrm{~km}$ or $20 \mathrm{~km}$ of roosting sites. Model-averaged standardized coefficients \pm 2 $\mathrm{SE}$ are in parentheses below variable names

\section{Supplementary Files}


This is a list of supplementary files associated with this preprint. Click to download.

- RoostManuscriptAppS.docx 